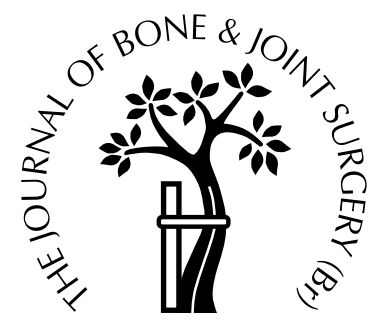

\title{
The coagulative and cardiorespiratory responses to reamed intramedullary nailing of isolated fractures
}

\author{
C. M. Robinson, C. A. Ludlam, D. C. Ray, D. G. Swann, J. Christie \\ From the Royal Infirmary of Edinburgh, Scotland
}

$\mathbf{W}$ e measured the changes during operation in seven markers of coagulation in a prospective series of 84 patients with fractures of the tibia or femur who were undergoing reamed intramedullary nailing. All patients were also continually monitored using transoesophageal echocardiography to assess marrow embolism. In a subset of $\mathbf{4 0}$ patients, intraoperative cardiopulmonary function was monitored, using pulmonary and systemic arterial catheterisation.

The procedure produced a significant increase in prothrombin time, activated partial thromboplastin time, the level of prothrombin fragments $\mathrm{F}_{1+2}$ and D-dimers, and a decrease in the fibrinogen level, suggesting activation of both the coagulation and fibrinolytic pathways. There was evidence of both platelet hyper-reactivity and depletion, as estimated by an increase in $\beta$-thromboglobulin levels and a decrease in the platelet count. In the patients who had invasive monitoring there was an incremental increase in mean pulmonary arterial pressure, with the changes being greatest during insertion of the guide-wire and reaming.

The change in markers of coagulation, pulmonary artery pressure and arterial oxygen partial pressures correlated with the intraoperative embolic response. Greater changes in these parameters were observed during stabilisation of pathological fractures and in those patients in whom surgery had been delayed for more than 48 hours.

Seven patients with pathological fractures developed more severe hypoxic episodes during reaming, which were associated with significantly greater arterial

C. M. Robinson, BMedSci, FRCS Ed(Orth), Senior Lecturer and Consultant Orthopaedic Surgeon

C. A. Ludlam, FRCP, Professor of Haematology

D. C. Ray, MD, FRCA, Consultant in Anaesthetics and Intensive Care

D. G. Swann, BSc, FRCA, Consultant in Anaesthetics and Intensive

Care

J. Christie, FRCS Ed, Consultant Orthopaedic Surgeon

Edinburgh Orthopaedic Trauma Unit, Royal Infirmary of Edinburgh,

Lauriston Place, Edinburgh EH3 9YW, UK.

Correspondence should be sent to $\mathrm{Mr}$ C. M. Robinson.

(C)2001 British Editorial Society of Bone and Joint Surgery 0301-620X/01/711593\$2.00 hypoxaemia, a fall in the right ventricular ejection fraction and an increase in the mean pulmonary artery pressure, pulmonary capillary wedge pressure, central venous pressure and the pulmonary vascular resistance index. These changes suggested that the patients had transient intraoperative right heart strain.

Eight patients developed significant postoperative respiratory compromise. They all had severe intraoperative embolic responses and, in the three who had invasive monitoring, there was a significantly greater increase in pulmonary artery pressure and alveolar-arterial oxygen gradient, and a fall in the ratio of arterial partial pressure of oxygen to the inspired oxygen concentration. Operative delay, intraoperative paradoxical embolisation and the scores for the severity of the coagulative and embolic responses were predictive of the development of postoperative respiratory complications on univariate logistic regression analysis. On multivariate analysis, however, only the embolic and coagulative scores were significant independent predictors of respiratory complications.

J Bone Joint Surg [Br] 2001;83-B:963-73.

Received 3 August 2000; Accepted after revision 29 November 2000

Intravasation of marrow contents into the venous circulation with subsequent embolisation to the lungs occurs to a greater or lesser degree in all procedures which involve reaming of the medullary canal. ${ }^{1,2}$ This process produces activation of the coagulation and fibrinolytic cascades, ${ }^{3-5}$ as well as the stimulation of other markers of inflammation. ${ }^{6,7}$ The pulmonary microcirculation acts as a filter for the embolic material, but becomes partially occluded as a consequence. The resulting effects on cardiopulmonary function and gaseous exchange have been studied in animal models, but are not well documented in man. ${ }^{8-12}$

The embolic load produced during most nailing procedures is mild and it is assumed that these responses are normally self-limiting and homeostatically controlled, so that most pass unnoticed when measured by standard clinical markers. A few patients with a fracture of a long bone, including those with pathological fractures or with a con- 
comitant chest injury, are at increased risk of developing adult respiratory distress syndrome. The pathophysiology of this condition remains incompletely understood, but excessive and uncontrolled activation of the coagulative, fibrinolytic and inflammatory pathways ${ }^{7,8,13-20}$ and haemodynamic changes within the lung parenchyma have all been implicated. ${ }^{21-23}$ It is a matter of debate as to whether or not the use of reamed intramedullary nailing in these situations increases the risk of the development of this complication and this has recently been the focus of clinical and laboratory-based research. ${ }^{8-12,24-28}$

Quantification of the normal responses to nailing in patients with isolated fractures, may enable us to understand the processes by which they become deranged in the multiply-injured patient who develops a post-traumatic lung syndrome. Our study aimed to quantify the coagulative and cardiorespiratory response to nailing of isolated fractures, using sensitive, invasive monitoring. We examined the correlation of these responses with the extent of the embolic load produced by nailing and also investigated whether there was an association between the changes in any of these parameters and the development of postoperative respiratory compromise.

\section{$\underline{\text { Patients and Methods }}$}

Over a period of three years we studied 84 patients ( 49 men and 35 women), with a mean age of 47.2 years, who had intramedullary nailing for isolated traumatic fractures of the tibia (group I, 34 patients) or of the femur (group II, 27 patients). Group III comprised 23 patients with pathological fractures of the femur. In these the primary tumour was in the breast in ten, in the bronchi in four and in the prostate in four. There was one case each of renal, thyroid and oesophageal tumours and of non-Hodgkin's lymphoma and myeloma. All the fractures were treated by nailing using standard techniques. ${ }^{29,30}$

Surgery for the fractures in groups I and II was performed on scheduled trauma lists. In 20 of these patients it was delayed for more than 48 hours. All the patients in group III underwent surgery after full evaluation of the extent of the spread of the tumour. No patient was receiving medication known to affect the coagulation pathways before operation. The same protocol of anaesthesia was used for all patients with standard induction and maintenance agents.

A total of 40 patients (14 in group I, 13 each in groups II and III) had preoperative cannulation of the pulmonary and peripheral arterial circulation using a Swan-Ganz pulmonary artery catheter (Baxter Healthcare Corporation, Pennsylvania) and a radial artery catheter (Arrow International Inc, California). Full approval of the local Ethical Committee was granted and informed consent for all invasive monitoring was obtained. Recording of the parameters of cardiopulmonary status and oxygenation was made after induction of anaesthesia but before the commencement of surgery, after surgical exposure but before instrumentation, after insertion of the guide-wire, after reaming, after insertion of the nail and following completion of surgery. Since there was no significant difference between any of the recordings made after induction of anaesthesia and after surgical exposure, the latter values were used as the baseline against which subsequent changes during instrumentation were compared.

The use of invasive monitoring allowed measurement of changes in heart rate, mean systemic arterial pressure, mean pulmonary arterial pressure, central venous pressure, right ventricular ejection fraction, venous admixture, systemic vascular resistance index, pulmonary vascular resistance index, cardiac index and pulmonary artery wedge pressure to be made during the procedures. The efficiency of gas exchange was estimated by calculation of the ratio of the arterial partial pressure of oxygen to the inspired oxygen concentration $\left(\mathrm{PaO}_{2} / \mathrm{FiO}_{2}\right.$ ratio), venous admixture (an estimate of the degree of physiological shunt) and the alveolararterial oxygen gradient (an estimate of the degree of mismatch of ventilation to perfusion). ${ }^{31,32}$

Intraoperative embolic episodes were monitored in all patients using a $5 \mathrm{MHz}$ biplanar transoesophageal echocardiography probe (Hewlett-Packard, Wokingham, UK). Representative videotape recordings of the observed embolic showers were made at times corresponding to the measurement of the cardiorespiratory parameters; these were later evaluated blindly using the Mayo Clinic System. ${ }^{33}$ In addition to consideration of each of these values individually, a score of the overall response was derived by summation of the intraoperative quantity of emboli for each patient.

Venous blood samples were taken before and after surgery for the measurement of platelets, prothrombin time (PT) and activated partial thromboplastin time (APTT). In addition to these standard tests, levels of fibrinogen, Ddimers (a fibrin degradation product which reflects lysis of stable cross-linked fibrin), prothrombin fragments $\mathrm{F}_{1+2}\left(\mathrm{PF}_{1+2}\right.$, by-product of prothrombin cleavage to thrombin) and $\beta$-thromboglobulins ( $\beta$-TG, which is liberated by $\alpha$-granules of activated platelets) were measured. As well as considering each of the individual markers of coagulation, an ordinal categorical score derived from all seven measured assays, reflecting the degree of operative activation of coagulation and fibrinolytic pathways, was used in subsequent analysis.

Postoperative estimations of arterial blood gas levels and a full blood count were undertaken on alternate days during the first postoperative week, or more often if indicated. The American-European Consensus Conference working definitions of adult respiratory distress syndrome (ARDS) and acute lung injury (ALI) were used. ${ }^{34}$ All patients were also monitored for systemic fat embolism, using the criteria of Gurd and Wilson ${ }^{35}$ for diagnosis.

Statistical analysis. All the information was analysed using the SPSS software package (SPSS Inc, Chicago, Illinois). 
Continuous data were expressed as means with $95 \%$ confidence intervals and categorical data as medians with interquartile ranges. The significance of time-trends for each of the measured variables during the nailing procedures within groups and between groups was tested using repeated-measures ANOVA and one-way ANOVA, respectively, for continuous data, and the Friedman two-way analysis of variance and Kruskal-Wallis test for categorical data. The extent of the correlation of variables was estimated using the Spearman rank-correlation method $\left(\mathrm{r}_{\mathrm{s}}\right)$. Linear and logistic regression methods were used to investigate the interactions beween variables and their ability to predict severe clinical response. For all analyses a p value of 0.05 or less for a type- 1 error was considered to be significant. The Tukey test was applied to all post-hoc analyses of the three groups.

\section{Results}

Embolic response. In groups I and II there was a minimal echogenic response before operation, whereas in group III there was a low-grade response (Table I). There was a significant increase in the amount, size and duration of embolic showers during insertion of the guide-wire, reaming and insertion of the nail (Friedman test, $\mathrm{p}<0.001$ ). The showering was typically short-lived and was subsiding at the time of the postoperative measurement. In groups I and II a minor response was characteristic, whereas in group III there was a significantly greater response during each of the four operative periods of measurement (Kruskal-Wallis test, $\mathrm{p}<0.001)$.

Paradoxical embolisation into the systemic circulation across a patent foramen ovale, only seen in the presence of high-grade embolisation, was observed in three patients (one in group II and two in group III) during reaming and insertion of the nail. There was a significantly increased embolic response (Kruskal-Wallis test, $\mathrm{p}<0.001$ ) in patients with traumatic fractures (groups I and II) who had delayed surgery compared with those whose operation was carried out within 48 hours of injury. There were no other significant differences in embolic response within the groups.

Changes in coagulation markers. Before operation, the levels of D-dimer, prothrombin fragments $\mathrm{F}_{1+2}$ and $\beta$-TG were elevated for all three groups and fibrinogen levels were above normal in groups II and III. The preoperative levels of all seven markers correlated positively with the postoperative levels. Most variability in postoperative levels, however, was not explained solely by the preoperative values on linear regression analysis, so that prediction of the operative change in levels was not possible.

Within all groups there was a significant postoperative increase (repeated-measures ANOVA, $\mathrm{p}<0.05$ ) in PT, Ddimers, $\mathrm{PF}_{1+2}$ and $\beta-\mathrm{TG}$ and a decrease in platelets and fibrinogen when compared with preoperative levels (Fig. 1). Although APTT $(\mathrm{p}<0.05)$ increased significantly when all groups were considered together, the differences were not significant within the three groups. The postoperative levels of $\mathrm{D}$-dimers and $\mathrm{PF}_{1+2}$ were greater and the platelet count lower in group III, when compared with groups I and II (one-way ANOVA, $\mathrm{p}<0.05$ ). For all groups considered together there was a positive correlation of the total intraoperative embolic score with the operative coagulation score $\left(r_{s}=0.74, p<0.001\right.$, Fig. 2a).

Patients with traumatic fractures (groups I and II) whose surgery had been delayed for more than 48 hours had a greater postoperative APTT (one-way ANOVA, $\mathrm{p}<0.05$ ), $\mathrm{PF}_{1+2}(\mathrm{p}<0.001)$ and $\beta-\mathrm{TG}(\mathrm{p}<0.001)$ and lower platelet counts $(p<0.001)$ and fibrinogen $(p<0.05)$ than those who underwent early surgery.

Systemic and pulmonary cardiovascular changes. Insertion of the guide-wire, reaming and insertion of the nail produced minor and statistically insignificant increases in mean heart rate, systemic arterial pressure and cardiac index, which returned towards preinstrumentation levels after operation in the 40 patients who were studied (Table II). Nailing did not produce a change in the mean systemic vascular resistance index.

There was a significant incremental rise in mean pulmonary arterial pressure during each of the four periods after baseline measurement (Fig. 3a); the pressure increase was largest during insertion of the guide-wire and reaming, and least during insertion of the nail (repeated-measures ANOVA, $p<0.05)$. The magnitude of the increase was significantly higher in group III than in groups I or II during insertion of the guide-wire, reaming and insertion of

Table I. Median echogenic scores for four measured time periods (interquartile ranges in parentheses) for the 84 patients undergoing reamed intramedullary nailing of isolated fractures

\begin{tabular}{lllll}
\hline Time period & $\begin{array}{l}\text { All groups } \\
(\mathbf{n}=\mathbf{8 4})\end{array}$ & $\begin{array}{l}\text { Group I } \\
(\mathbf{n = 3 4 )}\end{array}$ & $\begin{array}{l}\text { Group II } \\
(\mathbf{n}=\mathbf{2 7})\end{array}$ & $\begin{array}{l}\text { Group III } \\
(\mathbf{n}=\mathbf{2 3})\end{array}$ \\
\hline Preinstrumentation & $3(4)$ & $0(0)$ & $3(3)$ & $4(2)$ \\
After insertion of the guide-wire & $4(3)^{*}$ & $3(3)^{*}$ & $4(2.25)^{*}$ & $6(3)^{* \dagger}$ \\
After reaming & $4(2)^{*}$ & $4(0)^{*}$ & $4(2)^{*}$ & $7(2)^{* \dagger}$ \\
After insertion of the nail & $4(3)^{*}$ & $3(4)^{*}$ & $4(2)^{*}$ & $7(3)^{* \dagger}$ \\
Postoperative & $3(4)^{*}$ & $0(3)^{*}$ & $3(4)$ & $5(2)^{* \dagger}$ \\
\hline
\end{tabular}

* significant increase of echogenic score in comparison with preoperative score on Friedman test

$\dagger$ significant difference of group III from groups I and II on Kruskal-Wallis test 


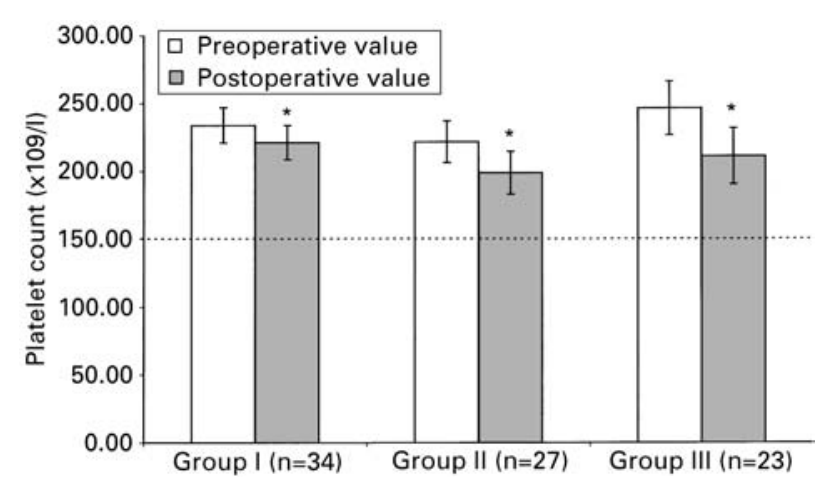

Fig. 1a

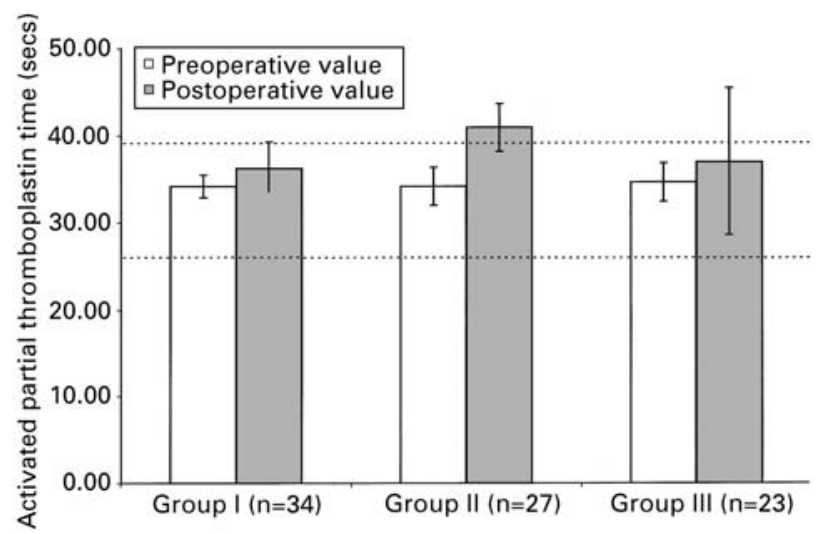

Fig. 1c

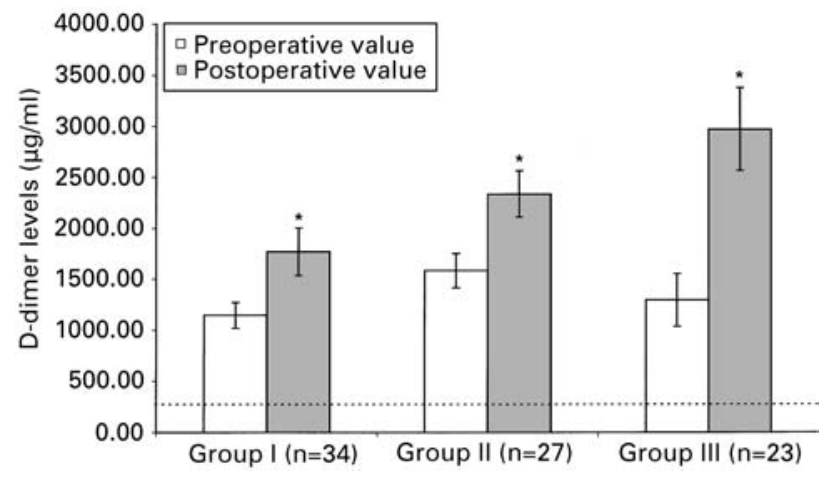

Fig. 1e

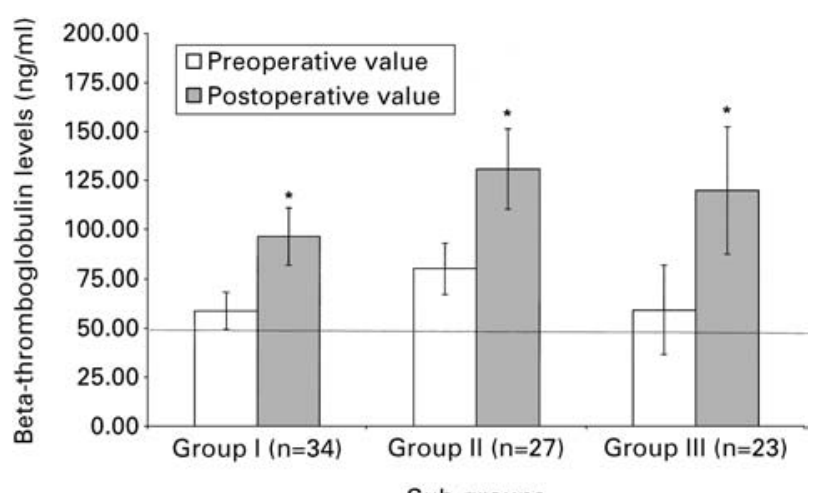

Fig. 19

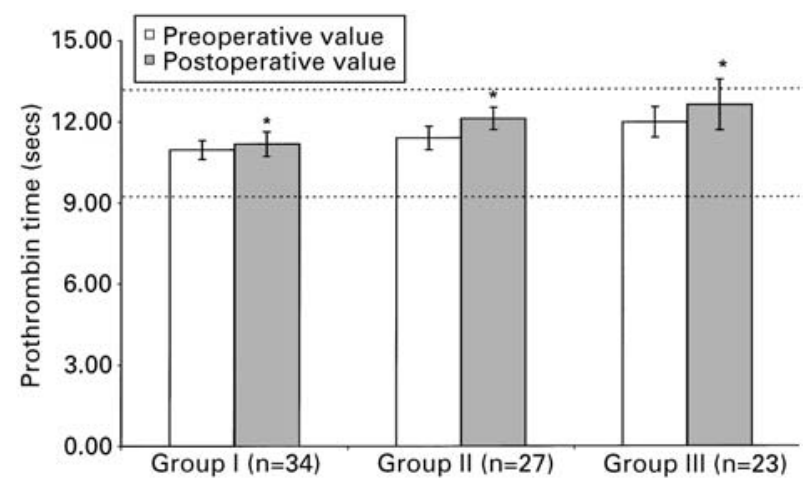

Fig. 1b

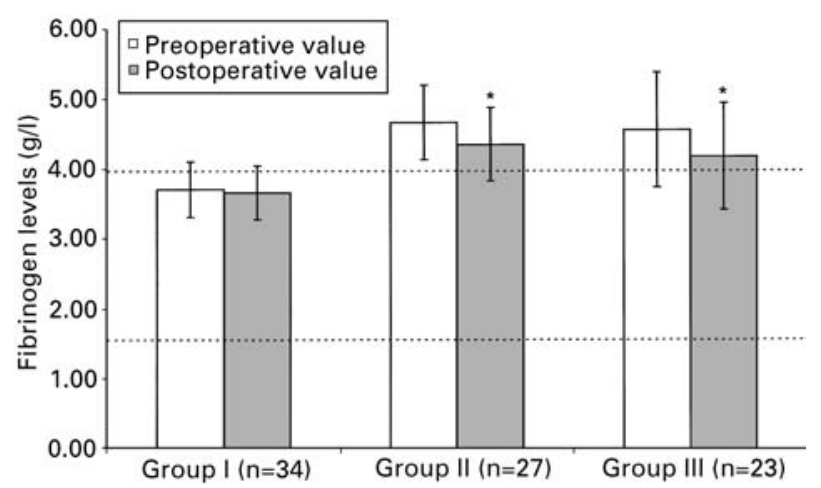

Fig. 1d

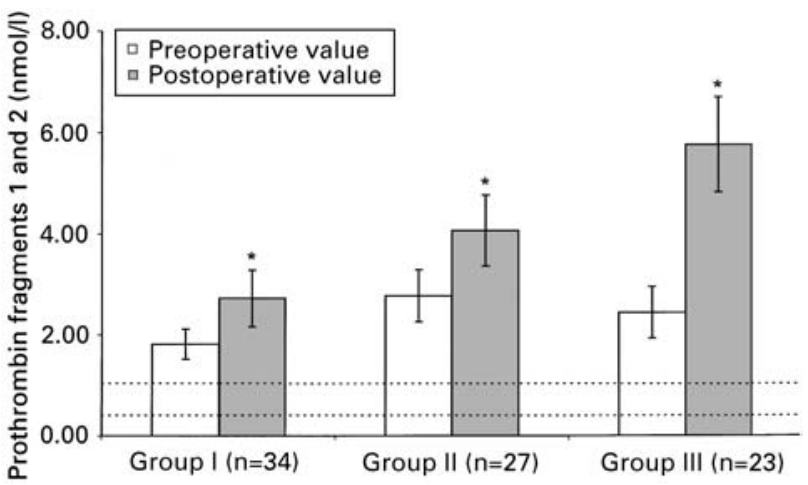

Fig. 1f

Graphs showing the pre- and postoperative a) platelet count, b) prothrombin time, c) APTT, d) fibrinogen levels, e) D-dimer levels, f) prothrombin fragments 1 and 2 and g) $\beta$-TG levels for the three groups $(*$, significant $(\mathrm{p}<0.05)$ increase from preoperative value; dotted line denotes normal laboratory reference values). 


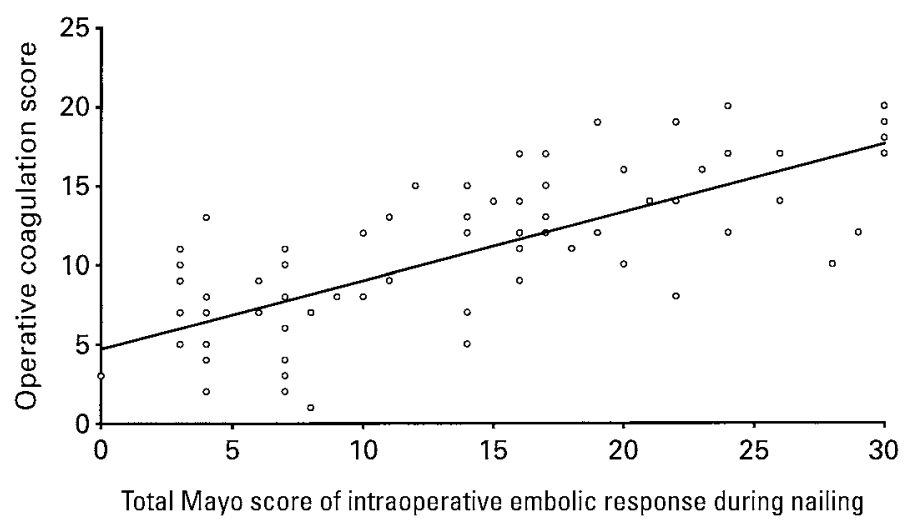

Fig. 2a

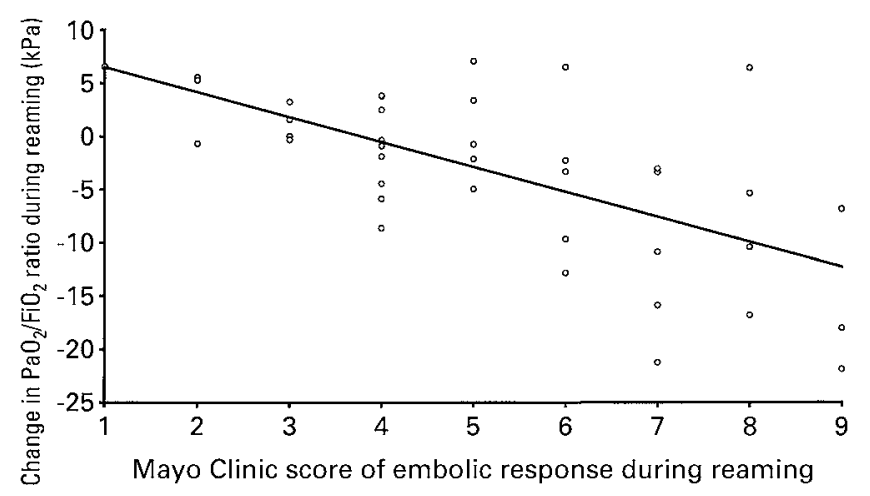

Fig. 2c

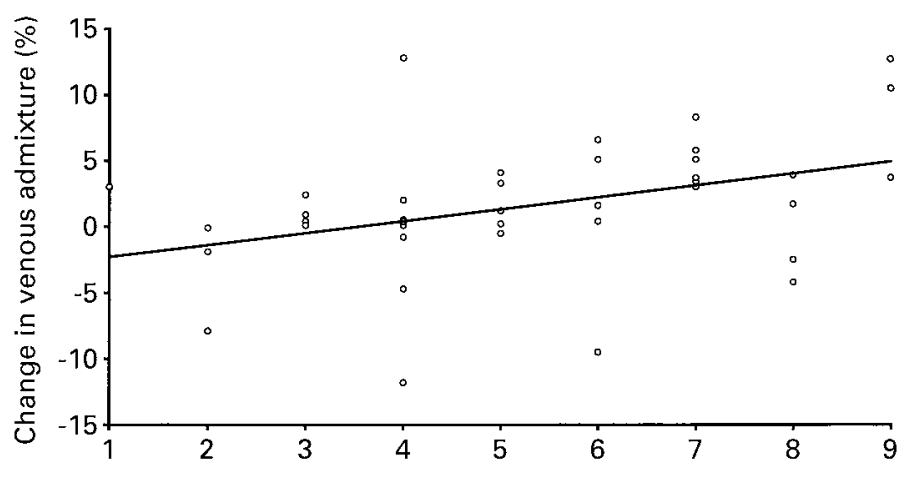

Mayo Clinic score of embolic response during reaming

Fig. 2e

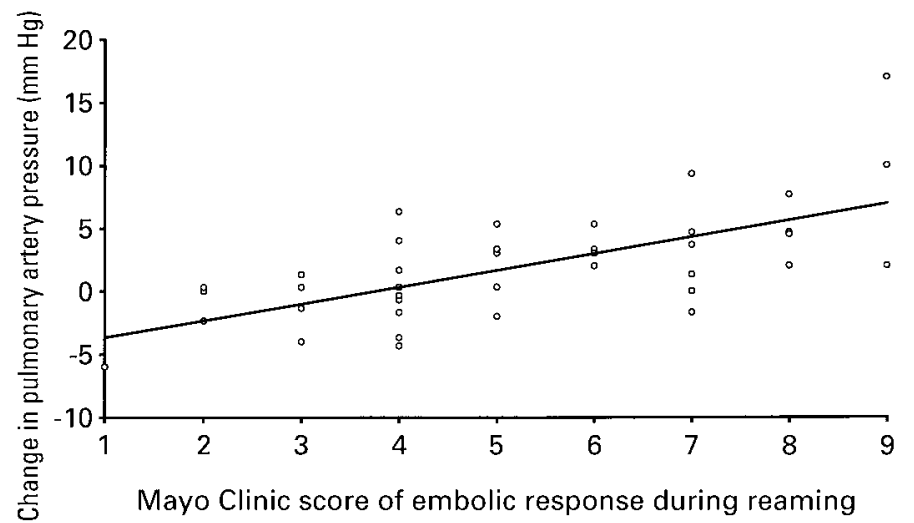

Fig. 2b

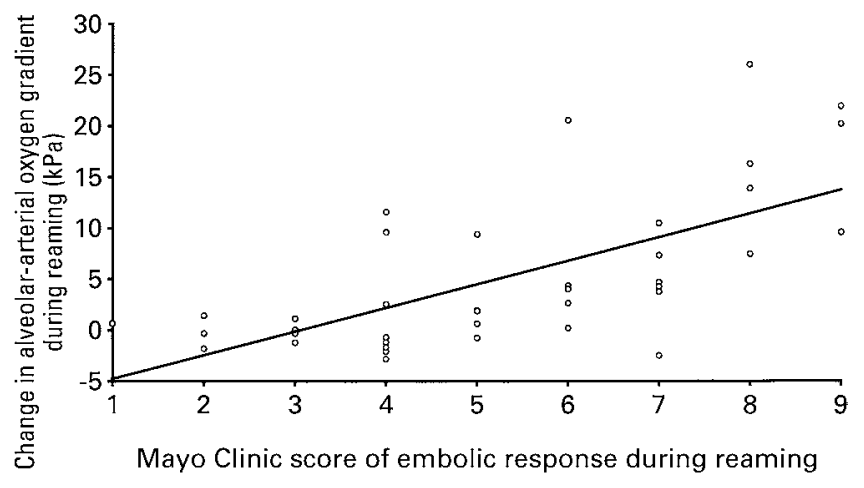

Fig. 2d

Graphs showing correlation between embolic response and a) the operative coagulation score during nailing, $b$ ) the change in pulmonary artery pressure during reaming, c) the $\mathrm{PaO}_{2} / \mathrm{FiO}_{2}$ ratio during reaming, d) the alveolar-arterial oxygen gradient during reaming and e) the change in venous admixture during reaming.

Table II. Mean values (95\% confidence interval) of indices of cardiovascular function during the nailing procedures for the 40 patients monitored

\begin{tabular}{|c|c|c|c|c|c|}
\hline Indices of cardiovascular function* & Preinstrumentation & $\begin{array}{l}\text { After insertion } \\
\text { of guide-wire }\end{array}$ & After reaming & $\begin{array}{l}\text { After insertion } \\
\text { of nail }\end{array}$ & Postoperative \\
\hline Heart rate (beats. $\min ^{-1}$ ) & $69.2(64.8$ to 73.6$)$ & 68.4 (64.2 to 72.7$)$ & 70.4 (66.0 to 74.9$)$ & 72.4 (67.8 to 77.0$)$ & 71.6 (66.7 to 76.5$)$ \\
\hline MSAP $(\mathrm{mmHg})$ & 74.8 (71.2 to 78.5$)$ & 76.3 (72.9 to 79.7$)$ & 78.6 (75.4 to 81.8$)$ & 77.51 (74.2 to 80.8$)$ & 77.6 (73.9 to 81.3$)$ \\
\hline Cardiac index $\left(\mathrm{L} \cdot \mathrm{min}^{-1} \mathrm{~m}^{-2}\right)$ & 3.2( & $3.2(2.9$ to 3.5$)$ & to 3.6$)$ & 3.3 (3.0 to 3.6$)$ & 3.4 (3.1 to 3.7$)$ \\
\hline SVRI (dynes.sec. $\left.\mathrm{cm}^{-5} \mathrm{~m}^{2}\right)$ & $1800(1624$ to 1970$)$ & 1834 (1656 to 2012 ) & $1800(1652$ to 1949$)$ & 1792 (1634 to 1952$)$ & 1767 (1595 to 1939$)$ \\
\hline PCWP (mmHg) & $11.4(10.4$ to 12.4$)$ & 11.7 (10.6 to 12.8$)$ & 12.3 (10.9 to 13.7$)$ & $11.8(10.7$ to 13.0$)$ & 11.5 (10.5 to 12.6$)$ \\
\hline Central venous pressure $(\mathrm{mmHg})$ & $8.1(7.1$ to 9.0$)$ & $8.3(7.3$ to 9.2$)$ & $8.7(7.5$ to 9.8$)$ & $8.2(7.2$ to 9.1$)$ & 8.5 (7.3 to 9.7$)$ \\
\hline Right ventricular ejection fraction (\%) & 36.7 (34.2 to 39.1$)$ & 37.3 (35.1 to 39.5$)$ & 35.6 (33.5 to 37.7$)$ & 36.7 (34.7 to 38.7$)$ & $37.3(35.1$ to 39.4$)$ \\
\hline
\end{tabular}

* MSAP, mean systemic arterial pressure; SVRI, systemic vascular resistance index; PCWP, pulmonary capillary wedge pressure 


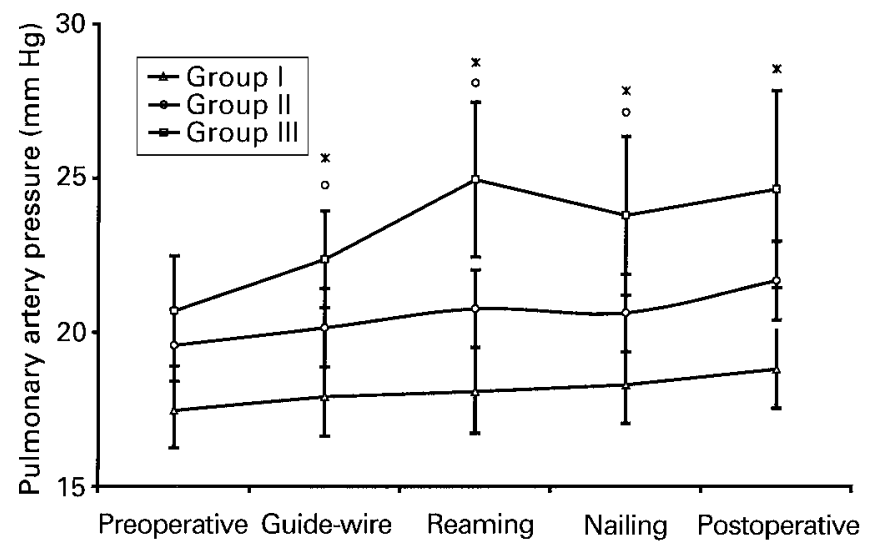

Fig. 3a

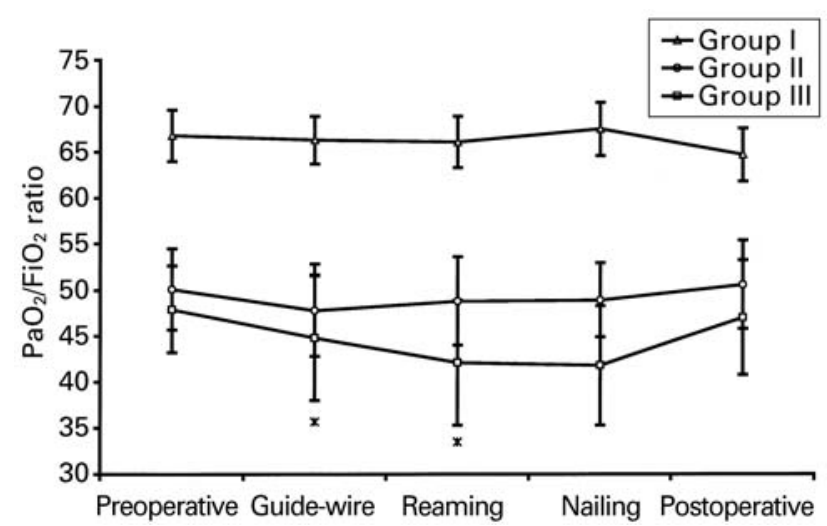

Fig. 3c

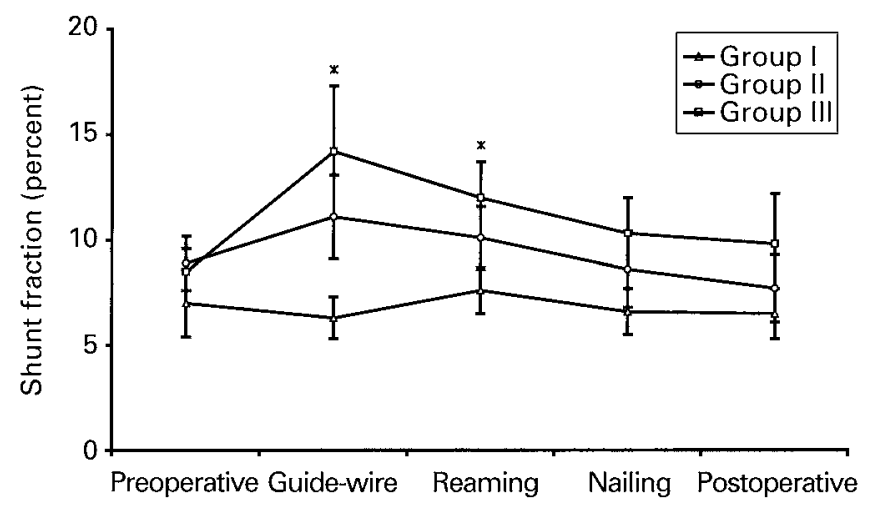

Fig. 3e

the nail (one-way ANOVA, $\mathrm{p}<0.05$ ). During reaming there was a positive correlation between the severity of the embolic response and the rise in pulmonary artery pressure $\left(r_{\mathrm{s}}=0.64, \mathrm{p}<0.001\right.$, Fig. $\left.2 \mathrm{~b}\right)$.

There was a statistically insignificant increase in mean pulmonary capillary wedge pressure during insertion of the guide-wire and reaming; the mean pressures subsequently returned towards baseline levels during insertion of the nail and after operation (Table II). There were no significant changes in the mean central venous pressure or right

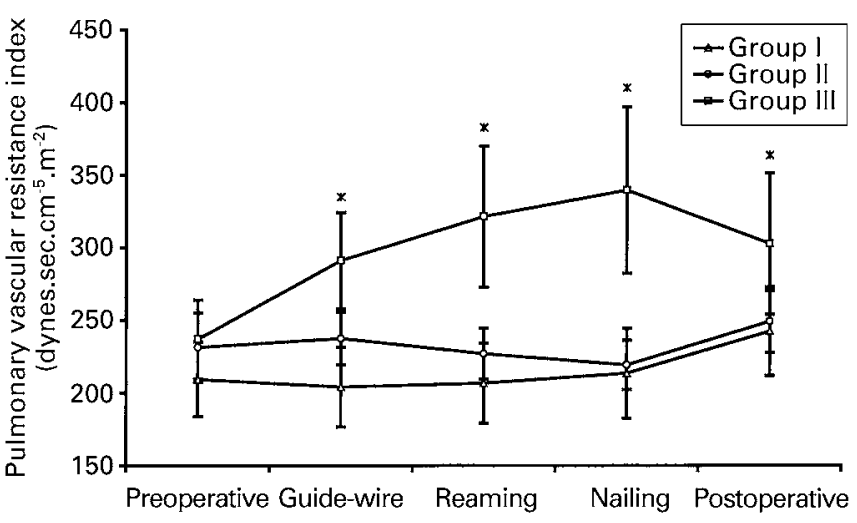

Fig. $3 b$

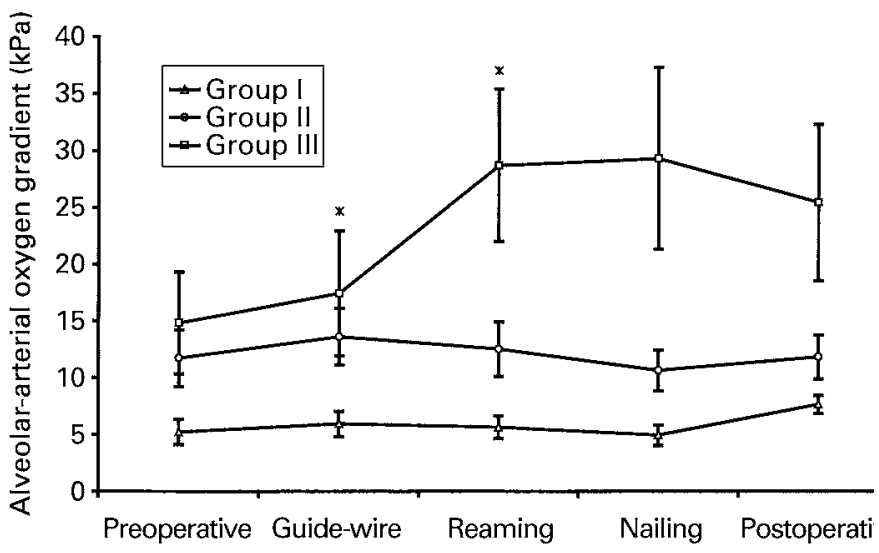

Fig. 3d

Graphs showing changes at each measurement period in a) mean pulmonary artery pressure (* significant increase, $\mathrm{p}<0.05$; o significantly greater increase in group III compared with groups I and II), b) pulmonary vascular resistance index (* significant increase, $p<0.05), c$ ) the $\mathrm{PaO}_{2} / \mathrm{FiO}_{2}$ ratio (* significant decrease, $\mathrm{p}<0.05$ ), d) alveolar-arterial oxygen gradient $(*$ significant increase, $\mathrm{p}<0.05)$ and e) venous admixture during nailing (* significant increase, $\mathrm{p}<0.05$ ).

ventricular ejection fraction for the study group as a whole (Table II). There was no significant change in the computed pulmonary vascular index resistance in groups I and II, although there was an incremental rise in this value after insertion of the guide-wire, after reaming and after insertion of the nail in group III (Fig. 3b).

Gas exchange. A slight fall in the $\mathrm{PaO}_{2} / \mathrm{FiO}_{2}$ ratio was seen in groups I and II during insertion of the guide-wire and reaming. In group III both insertion of the guide-wire and reaming produced a significant incremental fall in the 
Table III. Mean (95\% confidence interval) changes in measured indices of cardiopulmonary function during reaming in seven patients with severe hypoxic episodes associated with severe embolisation compared with the remaining 33 patients

\begin{tabular}{lll}
\hline Measured cardiopulmonary parameter & Hypoxic episodes group & Uneventful operative course \\
\hline Mean pulmonary artery pressure $(\mathrm{mmHg})$ & $7.9(3.4 \text { to } 12.5)^{*}$ & $0.8(-0.3$ to 1.8$)$ \\
Pulmonary vascular resistance index $\left(\right.$ dynes.sec. $\left.\mathrm{cm}^{-5} \mathrm{~m}^{2}\right)$ & $109.4(28.2 \text { to } 190.7)^{*}$ & $6.0(-13.5$ to 25.7$)$ \\
Venous admixture $(\%)$ & $4.9(0.9 \text { to } 10.8)^{*}$ & $0.6(-1.2$ to 2.5$)$ \\
Alveolar-arterial oxygen gradient $(\mathrm{kPa})$ & $15.6(8.5 \text { to } 22.7)^{*}$ & $2.9(1.0$ to 4.8$)$ \\
Right ventricular ejection fraction $(\%)$ & $-5.1(-9.4 \text { to }-0.9)^{*}$ & $-0.2(-2.2$ to 1.7$)$ \\
Central venous pressure $(\mathrm{mmHg})$ & $3.0(0.9 \text { to } 5.1)^{*}$ & $0.1(-0.6$ to 0.9$)$ \\
Pulmonary capillary wedge pressure $(\mathrm{mmHg})$ & $3.9(1.6 \text { to } 6.1)^{*}$ & $0.3(-0.5$ to 1.0$)$ \\
\hline
\end{tabular}

* significant difference of complication group from uncomplicated group (one-way ANOVA, $\mathrm{p}<0.05$ )

Table IV. Median echogenic scores for the eight patients with postoperative respiratory complications compared with the remaining 76 patients (interquartile ranges in parentheses)

\begin{tabular}{lll}
\hline Time period & Uncomplicated recovery group & Complications group \\
\hline Preinstrumentation & $0(3)$ & $5(1)^{*}$ \\
After insertion of the guide-wire & $4(3)$ & $6(4)^{*}$ \\
After reaming & $4(2)$ & $8(0.75)^{*}$ \\
After nailing & $4(2)$ & $8(1)^{*}$ \\
Postoperative & $3(4)$ & $7(2.75)^{*}$ \\
\hline
\end{tabular}

* significant difference of complication group from uncomplicated group on Kruskal-Wallis test $(\mathrm{p}<0.05)$

Table V. Mean (95\% confidence intervals) postoperative levels of coagulation markers for the eight patients with postoperative respiratory complications compared with the remaining 76 patients

\begin{tabular}{lcc}
\hline Coagulation parameter & Complications group & Uncomplicated recovery group \\
\hline Platelet count $\left(\times 10^{9} \cdot{ }^{-1} \mathrm{~L}\right)$ & $143.4(85.7 \text { to } 201.1)^{*}$ & $218.3(206.5$ to 230.2$)$ \\
Prothrombin time $(\mathrm{secs})$ & $14.5(10.8 \text { to } 18.3)^{*}$ & $11.6(11.3$ to 11.9$)$ \\
Activated partial thromboplastin time $(\mathrm{secs})$ & $52.48(20.7 \text { to } 84.2)^{*}$ & $36.4(34.7$ to 38.1$)$ \\
Fibrinogen $(\mathrm{g} / \mathrm{L})$ & $2.3(1.4 \text { to } 3.2)^{*}$ & $4.2(3.8$ to 4.6$)$ \\
D-dimers $(\mu \mathrm{g} / \mathrm{ml})$ & $3103.5(1513.8 \text { to } 4693.2)^{*}$ & $2165.5(1953.9$ to 2377.1$)$ \\
Prothrombin fragments $\mathrm{F}_{1+2}(\mathrm{nmol} / \mathrm{L})$ & $7.0(4.7 \text { to } 9.2)^{*}$ & $3.7(3.1$ to 4.2$)$ \\
$\beta$-thromboglobulins $(\mathrm{ng} / \mathrm{ml})$ & $171.1(124.0 \text { to } 218.3)^{*}$ & $107.7(93.0$ to 122.5$)$ \\
\hline
\end{tabular}

* significant difference of complication group from uncomplicated group (one-way ANOVA, p $<0.05$ )

$\mathrm{PaO}_{2} / \mathrm{FiO}_{2}$ ratio (repeated-measures ANOVA, $\mathrm{p}<0.05$, Fig. $3 \mathrm{c})$, and an increase in the alveolar-arterial oxygen gradient $(\mathrm{p}<0.05$, Fig. $3 \mathrm{~d})$ and venous admixture $(\mathrm{p}<0.05$, Fig. $3 \mathrm{e})$. These changes stabilised during insertion of the nail and returned towards baseline values at the end of surgery. There was a significant negative correlation between the change in the $\mathrm{PaO}_{2} / \mathrm{FiO}_{2}$ ratio and both the embolic response during reaming $\left(r_{s}=-0.63, p<0.001\right.$, Fig. $\left.2 c\right)$ and the coagulation score $\left(r_{s}=-0.73, p<0.001\right)$. There was also a positive correlation of both the change in the alveolararterial oxygen gradient $\left(r_{s}=0.67, p<0.001\right.$, Fig. $\left.2 d\right)$ and venous admixture $\left(r_{s}=0.51, p<0.001\right.$, Fig. $\left.2 e\right)$ with the embolic response during reaming. The partial pressure of arterial carbon dioxide did not change significantly during the procedures.

Clinically significant responses. Of the 40 patients who had invasive monitoring, 13 had severe intraoperative embolic responses (Mayo score of $\geq 7$ ). Seven of these patients, all in group III, developed severe hypoxic episodes during reaming ( $>25 \%$ fall in $\mathrm{PaO}_{2} / \mathrm{FiO}_{2}$ ratio to an absolute value below $40 \mathrm{kPa}$ ). These episodes were associated with a significantly greater increase in mean pulmonary artery pressure, pulmonary capillary wedge pressure, central venous pressure, pulmonary vascular resistance index, venous admixture and alveolar-arterial oxygen gradient and a greater fall in right ventricular ejection fraction (Table III).

Eight of the total study group developed significant postoperative, non-infective respiratory complications. There was one in group III who died immediately after surgery and seven others ( 2 in group I, 2 in group II and 3 in group III), of whom three developed ARDS and four ALI. Four of these patients had evidence of systemic fat embolisation and one died from fulminant ARDS on the fourth postoperative day. All the others recovered with supportive therapy. 
A comparison of this subgroup of patients with the remainder is given in Tables IV and V. The patients with severe responses had significantly greater intraoperative embolic scores for each of the four time periods (KruskalWallis test, $\mathrm{p}<0.05)$. These patients had a significantly greater operative increase in PT, APTT, D-dimers, $\mathrm{PF}_{1+2}$ and $\beta$-TG and a decrease in platelets and fibrinogen (oneway ANOVA, $p<0.05$ ). Changes consistent with a clinical diagnosis of disseminated intravascular coagulation were present in five. Severe clinical responses occurred in two of the three patients with paradoxical embolisation and four of the 20 with traumatic fractures who had surgery delayed for more than 48 hours. Three of these patients had undergone intraoperative invasive monitoring and all had severe intraoperative embolic responses associated with hypoxic episodes, with a significant increase in pulmonary artery pressure and alveolar-arterial oxygen gradient and a fall in the $\mathrm{PaO}_{2} / \mathrm{FiO}_{2}$ ratio during reaming.

On univariate logistic regression analysis, the embolic score, the occurrence of paradoxical embolisation and an operative delay of more than 48 hours were predictive of a significant postoperative clinical response $(p<0.05)$. Although none of the seven markers of coagulation was predictive in isolation, the coagulation score derived from all seven variables was predictive of outcome $(p<0.05)$. In a multivariate model, which included all these, only the embolic score $(\mathrm{p}<0.05)$ and coagulation score $(\mathrm{p}<0.05)$ were significant independent predictors of postoperative respiratory compromise.

\section{Discussion}

Reamed intramedullary nailing remains a safe, effective treatment for most isolated fractures of long bones, despite producing displacement and intravasation of marrow contents into the venous circulation. ${ }^{1,2}$ Since only a very few patients develop clinically significant side-effects from this, one of the major roles of the pulmonary vasculature must be to filter these emboli from the systemic venous circulation. This partial occlusion of the pulmonary microcirculation produces temporary impairment of right heart function and gaseous exchange. ${ }^{2,36}$ In addition, marrow contents are known to be thrombogenic causing activation of the coagulation and fibrinolytic pathways, as well as that which would be expected from the surgical stimulus alone., ${ }^{2,37}$ Although the coagulative and cardiopulmonary effects of replacement arthroplasty of the hip and knee have previously been examined, ${ }^{38,39}$ this is the first clinical study to attempt specifically to quantify these effects in patients undergoing reamed nailing.

We have shown that reamed nailing is associated with the activation of coagulation pathways. The typical coagulative response was one of prolongation of PT and APTT, with elevation of the levels of $\mathrm{PF}_{1+2}$ and D-dimers, and a decrease in fibrinogen. Such changes are consistent with activation of both the coagulative and fibrinolytic pathways with consequent consumption of clotting factors and inhibitors. There was also an increase in the level of $\beta$-TG and a fall in the platelet count, reflecting both the activation and consumption of platelets. This anticipated involvement of such pathways reflects the normal physiological response to trauma, producing activation of the coagulation cascades and platelets to control haemorrhage, and activation of the fibrinolytic pathways to prevent widespread thrombosis. ${ }^{40}$ The degree of intraoperative coagulative activation during nailing correlated with the severity of the embolic response and this could also be anticipated, given the known coagulative effects of intravasation of marrow contents. ${ }^{3-5}$

The deleterious clinical effect of surgical delay has been described in patients with fractures of the femur undergoing nailing. ${ }^{41}$ Although operative delay was not significantly predictive of the development of postoperative respiratory compromise when corrected for other variables on logistic regression analysis in our series, all four patients with traumatic fractures (groups I and II) who developed this complication had delayed surgery. In addition, patients whose surgery had been delayed showed a greater intraoperative embolic and coagulative response. This provides further support for the stabilisation of isolated fractures of the tibia and femur within 48 hours of injury.

The association of disseminated malignancy with abnormalities of coagulation is also well recognised, particularly in metastatic adenocarcinoma in which a thrombotic diathesis may be a presenting feature. ${ }^{42}$ We were unable to detect any substantial differences in the degree of preactivation in those patients with pathological fractures in our study. It is possible that the heterogenous nature of the primary malignancies included could have been a confounding factor. However, a more severe intraoperative embolic response, a coagulative response and arterial hypoxaemia with more significant respiratory complications were seen in this group of patients. It is probable that the embolic material liberated during reaming is more thrombogenic because of the presence of tumour cells, producing a correspondingly greater activation of the coagulation cascades. ${ }^{4,13,43}$

Nailing procedures also produced an incremental increase in pulmonary artery pressures which correlated with the severity of the intraoperative embolic response. Although the greatest changes in pulmonary pressures corresponded to the periods of maximal embolisation, it is unclear whether the pressure changes were simply due to the mechanical blockage of vessels. The reserve of the pulmonary vascular bed is considerable, with many capillaries unfilled at rest, and it has been estimated that half the pulmonary circulation can be obstructed by emboli before there is a substantial rise in pulmonary artery pressure. ${ }^{31,32}$ In our study, pulmonary arterial pressure rose, even in the presence of a relatively minor embolic response, and it therefore seems likely that factors such as vasoconstriction, resulting from either hypoxia or the local release of vasoactive mediators, or as a reflex response from the sympathetic nervous system, may also be important in the genesis of this effect. ${ }^{32,44,45}$ 
Despite the considerable increase in pulmonary artery pressure, this appeared to be self-limiting in most traumatic tibial and femoral fractures (groups I and II), with no evidence of right ventricular dysfunction or of an effect on gas exchange. In pathological fractures (group III), however, the nailing procedures produced hypoxic episodes (diminished $\mathrm{PaO}_{2} / \mathrm{FiO}_{2}$ ratio) and an increase in alveolararterial oxygen difference, reflecting a degree of ventilation-perfusion inequality. An increased alveolar-arterial oxygen difference can be caused by both abnormally low or abnormally high ventilation-perfusion ratios within the lung. From animal studies ${ }^{44-46}$ it would appear that after embolisation the hypoxia is at least partially attributable to a reduced ventilation-perfusion ratio in the non-embolised regions of the lung, as a result of their increased blood flow (increased physiological shunt); blood is diverted from regions with reduced blood flow as a result of embolisation and there is also a compensatory reflex reduction in ventilation of the underperfused areas, as a result of reflex bronchoconstriction. ${ }^{32}$ This view is supported by our finding of increased venous admixture during insertion of the guidewire and reaming in patients with pathological fractures. Hypoxia may also have been produced by an increased ventilation-perfusion ratio as a result of residual ventilation in areas of embolisation (increased physiological dead space). ${ }^{32,36}$

Patients with pathological fractures experienced more significant hypoxic episodes than those with traumatic fractures, which may be explained by the greater embolic response and change in pulmonary artery pressure, producing ventilation-perfusion mismatch. ${ }^{46}$ The cause of the hypoxaemia after embolisation is still not fully understood and other factors may contribute. These may include diffusion impairment in the recruited pulmonary vessels with high flow rates, the local release of inflammatory mediators causing interstitial and alveolar oedema and the opening up of latent pulmonary arteriovenous anastomoses, as a result of the high pulmonary artery pressure. ${ }^{32,36,47,48}$

Seven patients with pathological fractures, who received invasive monitoring, developed more significant hypoxic episodes during periods of high-grade embolism which were associated with a greater increase in mean pulmonary artery pressure, venous admixture (shunt) and alveolararterial oxygen gradient when compared with the remainder of the monitored patients. There was also a significant fall in right ventricular ejection fraction and a rise in central venous pressure and pulmonary artery wedge pressure when compared with the whole group. The changes in these parameters suggest a pattern of right ventricular strain as a result of increased right ventricular afterload because of the greater embolic response.

Our findings indicate that the intraoperative cardiopulmonary response to nailing is predictable and proportional to the severity of the embolic generation. After relatively minor embolisation, a benign self-limiting rise in pulmonary artery pressure is seen without hypoxia (level I).
With more significant emboli the increase in pulmonary pressure is greater and accompanied by hypoxia and signs of right ventricular strain in some patients (level II). Despite the evidence of a more substantial cardiopulmonary response, only three of the seven patients showing this developed evidence of significant postoperative respiratory compromise. This level is still fully reversible and only provides a partial indication of the risk. With more severe embolisation, progressive right-heart strain may lead to right-sided and then biventricular failure (level III). Although this sequence of events was not seen in our series, it has previously been reported in patients with ARDS after trauma and during cemented arthroplasty. ${ }^{21-23,49,50}$ We have since observed this progression in two patients undergoing stabilisation of pathological fractures.

Postoperative respiratory compromise, not attributable to infective causes or cardiac failure, was seen in eight patients. These included one who died immediately after operation with fulminant fat embolism, and seven with postoperative respiratory compromise, four of whom had evidence of systemic embolisation. Although severe clinical responses were associated with paradoxical embolisation and operative delay, only the scores of embolic and coagulative response remained significant when included in a logistic regression model. The effect appeared to be synergistic; a severe embolic response alone was not associated with clinical effects in the absence of significant activation of coagulation pathways. This finding is supported by other studies which suggest that embolic material in itself is insufficient to generate a significant adverse clinical response and requires other 'triggering' factors. $^{51,52}$

Coagulopathy has been implicated for a long time in the pathogenesis of post-traumatic lung insufficiency states, including the fat embolus syndrome. ${ }^{814-18}$ A common pathway for these more severe responses may be that preactivation of the coagulative pathways, platelets and inflammatory mediators is present, producing an enhanced activation of these pathways after nailing. ${ }^{7,19}$ It has previously been demonstrated that disseminated intravascular coagulation and platelet sequestration occur in the lungs during post-traumatic ALI or ARDS, ${ }^{5,53,54}$ and this may be as a consequence of the thromboplastic effect of the emboli liberated into the bloodstream. Five of our patients with severe clinical responses had a haematological picture consistent with the diagnosis of disseminated intravascular coagulation and significant changes were apparent in the other three.

Some authors have attributed post-traumatic respiratory insufficiency entirely to disseminated intravascular coagulation within the lung, producing microthrombosis and pneumocyte damage. ${ }^{14,15}$ Most series report that ARDS and disseminated intravascular coagulation often coexist, with $20 \%$ of patients sharing features of both. ${ }^{55,56}$ A generalised coagulopathic state may also explain how the emboli, which are normally filtered from the systemic circulation 
by the lung parenchyma, may produce signs of systemic embolisation in the absence of a patent foramen ovale. As yet, however, we cannot establish whether the coagulative changes are primarily involved in the pathogenesis of the severe postoperative responses or are simply a reflection of a more generalised systemic inflammatory response to trauma. Many inflammatory mediators also have procoagulant effects $^{56-58}$ and are implicated in the pathogenesis of posttraumatic ARDS. ${ }^{6,7,58,59}$ The interactions are clearly complex and require further study.

We have developed a model for monitoring the coagulative and cardiopulmonary effects of reamed nailing, but further work is required to extend its use to patients at high risk of developing respiratory complications after trauma, including patients with chest injuries and a fracture of the femur or tibia. Ultimately, we need to identify, reliably, the preoperative factors which predict the risk of respiratory compromise after nailing, so that alternative methods of stabilisation of the fracture can be used in these patients.

Invasive monitoring is not routinely justified during the surgical treatment of most isolated fractures of the femur and tibia because the marginal additional benefits from its use do not outweigh the risks of producing a pneumothorax or an arrhythmia, or of introducing sepsis through cannulation of the pulmonary artery. In 'high-risk' cases, we feel that monitoring the severity of embolism using transoesophageal echocardiography combined with peripheral arterial and central venous cannulation to monitor filling pressures and oxygenation, will provide an early indication of those patients likely to develop significant postoperative respiratory complications. Perioperative monitoring of the activation of the coagulation and fibrinolytic pathways also provides further information which is of prognostic value. We now use such an approach routinely in those patients undergoing reamed nailing for pathological fractures and in those patients with known patency of the foramen ovale.

We wish to acknowledge the financial support provided by Grants from the Wishbone Trust and the Scottish Orthopaedic Research Trust Into Trauma (SORT-IT).

No benefits in any form have been received or will be received from a commercial party related directly or indirectly to the subject of this article.

\section{References}

1. Wenda K, Henrichs KJ, Biegler M, Erbel R. Nachweis von markembolien während oberschenkelmarknagelungen mittels transösophagealer echokardiographie. Unfallchirurgie 1989;15:73-6.

2. Christie J, Robinson CM, Pell ACH, McBirnie J, Burnett R. Transcardiac echocardiography during invasive intramedullary procedures. J Bone Joint Surg [Br] 1995;77-B:450-5.

3. Saldeen T. Intravascular coagulation in the lungs in experimental fat embolism. Acta Chir Scand 1969;135:653-62.

4. Pape H-C, Bartels M, Pohlemann T, et al. Coagulatory response after femoral instrumentation after severe trauma in sheep. J Trauma 1998;45:720-8.

5. Heim D, Regazzoni P, Tsakiris DA, et al. Intramedullary nailing and pulmonary embolism: does unreamed nailing prevent embolisation?: an in-vivo study in rabbits. J Trauma 1995;38:899-906.

6. Strecker W, Gonschorek O, Fleischmann W, et al. Thromboxaneco-factor of pulmonary disturbances in intramedullary nailing. Injury 1993;24:Suppl 3:68-72.
7. Giannoudis PV, Smith RM, Bellamy MC, et al. Stimulation of the inflammatory system by reamed and unreamed nailing of femoral fractures: an analysis of the second hit. J Bone Joint Surg $[\mathrm{Br}]$ 1999;81-B:356-61.

8. Pape H-C, Auf'm'Kolk M, Paffrath T, et al. Primary intramedullary femur fixation in multiple trauma patients with associated lung contusion: a cause of post-traumatic ARDS? J Trauma 1993;34:540-8.

9. Neudeck F, Wozasek GE, Obertacke U, Thumher M, Schlag G. Nailing versus plating in thoracic trauma: an experimental study in sheep. J Trauma 1996;40:980-4.

10. Duwelius PJ, Huckfeldt R, Mullins RJ, et al. The effects of femoral intramedullary reaming on pulmonary function in a sheep lung model. J Bone Joint Surg [Am] 1997;79-A:194-202.

11. Wolinsky PR, Banit D, Parker RE, et al. Reamed intramedullary femoral nailing after induction of an 'ARDS-like' state in sheep: effect on clinically applicable markers of pulmonary function. J Orthop Trauma 1998;12:169-75.

12. Elmaraghy AW, Aksenov S, Byrick RJ, Richards RR, Schemitsch EH. Pathophysiological effect of fat embolism in a canine model of pulmonary contusion. J Bone Joint Surg [Am] 1999;81-A:1155-64.

13. Nyska M, Klin B, Margulies JY, Fast A, Floman Y. Disseminated intravascular coagulopathy in patients with cancer undergoing operation for pathological fractures of the hip. Int Orthop 1987;11:179-81.

14. Saldeen T. Fat embolism and signs of intravascular coagulation in a post-traumatic autopsy material. J Trauma 1970;10:273-86.

15. Bradford DS, Foster RR, Nossel HL. Coagulation alterations, hypoxaemia, and fat embolism in fracture patients. J Trauma 1970;10:307-21.

16. Lilienberg G, Rammer L, Saldeen T, Thoren L, Uddstromer L. Intravascular coagulation and inhibition of fibrinolysis in fat embolism. Acta Chir Scand 1970;136:87-90.

17. Peltier LF. Fat embolism: a perspective. Clin Orthop 1988; 232: 263-70.

18. Idell S, James KK, Levin EG, et al. Local abnormalities in coagulation and fibrinolytic pathways predispose to alveolar fibrin deposition in the adult respiratory distress syndrome. J Clin Invest 1989;84:695-705.

19. Waydhas C, Nast-Kolb D, Trupka A, et al. Post-traumatic inflammatory response, secondary operations, and late multiple organ failure. J Trauma 1996;40:624-30.

20. Giannoudis PV, Smith RM, Banks RE, et al. Stimulation of inflammatory markers after blunt trauma. Br J Surg 1998;85:986-90.

21. Eddy AC, Rice CL, Anardi DM. Right ventricular dysfunction in multiple trauma victims. Am J Surg 1988;155:712-5.

22. Dhainut JF, Brunet F. Right ventricular performance in adult respiratory distress syndrome. Eur Respir J Suppl 1990;11:490-5.

23. Steltzer H, Krafft P, Fridrich P, Hiesmayr M, Hammerle AF. Right ventricular function and oxygen transport patterns in patients with acute respiratory distress syndrome. Anaesthesia 1994;49:1039-45.

24. Pape HC, Dwenger A, Regel G, Remmers D, Tscherne H. Intramedullary femoral nailing in sheep: does severe injury predispose to pulmonary dysfunction? Eur J Surg 1995;161:163-71.

25. Pelias ME, Townsend MG, Flancbaum L. Long bone fractures predispose to pulmonary dysfunction in blunt chest trauma despite early operative fixation. Surgery 1992;111:576-9.

26. Bosse MJ, MacKenzie EJ, Riemer BL, et al. Adult respiratory distress syndrome, pneumonia, and mortality following thoracic injury and a femoral fracture treated either with intramedullary nailing with reaming or with a plate: a comparative study. J Bone Joint Surg [Am] 1997;79-A:799-809.

27. Boulanger BR, Stephen D, Brenneman FD. Thoracic trauma and early intramedullary nailing of femur fractures: are we doing harm? $J$ Trauma 1997;43:24-8.

28. Carlson DW, Rodman GH Jr, Kaehr D, Hage J, Misinski M. Femur fractures in chest-injured patients: is reaming contraindicated? $J$ Orthop Trauma 1998;12:164-8.

29. Christie J, Court-Brown C, Kinninmonth AWG, Howie CR. Intramedullary locking nails in the management of femoral shaft fractures. J Bone Joint Surg [Br] 1988;70-B:206-10.

30. Court-Brown CM, Christie J, McQueen MM. Closed intramedullary tibial nailing: its use in closed and type I open fractures. $J$ Bone Joint Surg [Br] 1990;72-B:605-11.

31. West JB. Pulmonary pathophysiology: the essentials. 5th ed, Baltimore: Lippincott Williams and Wilkins, 1998. 
32. Lumb AB. Nunn's applied respiratory physiology. 5th ed. Oxford etc: Butterworth-Heinemann, 1999.

33. Ereth MH, Weber JG, Abel MD, et al. Cemented versus noncemented total hip arthroplasty: embolism, haemodynamics, and intrapulmonary shunting. Mayo Clin Proc 1992;67:1066-74.

34. Bernard GR, Artigas A, Brigham KL, et al. The American-European Consensus Conference on ARDS: definitions, mechanisms, relevant outcomes and clinical trial co-ordination. Am J Respir Crit Care Med 1994;149:818-24.

35. Gurd AR, Wilson RI. The fat embolism syndrome. J Bone Joint Surg [Br] 1974;56-B:408-16.

36. Greenbaum R, Nunn JF, Prys-Roberts C, Kelman GR, Silk FF. Cardipulmonary function after fat embolism. $\mathrm{Br} J$ Anaes 1965;37:554-5.

37. Wocasek GE, Simon P, Redl H, Schlag G. Intramedullary pressure changes and fat intravasation during intramedullary nailing: an experimental study in sheep. J Trauma 1994;36:202-7.

38. Lopez-Duran L, Garcia-Lopez A, Duran L, et al. Cardiopulmonary and haemodynamic changes during total hip arthroplasty. Int Orthop 1997;21:253-8.

39. Berman AT, Parmet JL, Harding SP, et al. Emboli observed with use of transesophageal echocardiography immediately after tourniquet release during total knee arthroplasty with cement. J Bone Joint Surg [Am] 1998;80-A:389-96.

40. Innes D, Sevitt S. Coagulation and fibrinolysis in injured patients. $J$ Clin Path 1964;17:1-13.

41. Bone LB, Johnson KD, Weigelt J, Scheinberg R. Early versus delayed stabilisation of femoral fractures: a prospective randomised study. J Bone Joint Surg [Am] 1989;71-A:336-40.

42. Bick RL. Coagulation abnormalities in malignancy: a review. Semin Thromb Hemost 1992;18:353-72.

43. Kerr PS, Jackson M, Atkins M. Cardiac arrest during intramedullary nailing for femoral metastases. J Bone Joint Surg [Br] 1993;75-B:9723 .

44. Dantzker DR, Wagner PD, Tornabene VW, Alazraki NP, West JB. Gas exchange after pulmonary thromboembolization in dogs. Circ Res 1978;42:92-103.

45. Parker FB, Wax SD, Kusajima K, Webb WR. Hemodynamic and pathological findings in experimental fat embolism. Arch Surg 1974;108:70-4.
46. D'Alonzo GE, Bower JS, DeHart P, Dantzker DR. The mechanisms of abnormal gas exchange in acute massive pulmonary embolism. Am Rev Respir Dis 1983;128:170-2.

47. Niden AH, Aviado DM. Effects of pulmonary embolism on the pulmonary circulation with special reference to arteriovenous shunts in the lung. Circ Res 1956;4:67-73.

48. Prys-Roberts C, Greenbaum R, Nunn JF, Kelman GR. Disturbances of pulmonary function in patients with fat embolism. J Clin Pathol Suppl (R Coll Path) 1970;4:143-9.

49. Sturm JA, Lewis FR, Trentz O, et al. Cardiopulmonary parameters and prognosis after severe multiple trauma. J Trauma 1979;19:305-18.

50. Byrick RJ, Forbes D, Waddell JP. A monitored cardiovascular collapse during cemented total knee replacement. Anesthesiology 1986;65:213-6.

51. Schemitsch EH, Jain R, Turchin DC, et al. Pulmonary effects of fixation of a fracture with a plate compared with intramedullary nailing: a canine model of fat embolism and fracture fixation. J Bone Joint Surg [Am] 1997;79-A:984-96.

52. Aoki N, Soma K, Shindo M, Kurosawa T, Ohwada T. Evaluation of potential fat emboli during placement of intramedullary nails after orthopaedic fractures. Chest 1998;113:178-81.

53. Heffner JE, Sahn SA, Repine JE. The role of platelets in the adult respiratory distress syndrome: culprits or bystanders? Am Rev Respir Dis 1987; 135:482-92.

54. Bone RC, Francis PB, Pierce AK. Intravascular coagulation associated with the adult respiratory distress syndrome. Am J Surg 1976;61:585-9.

55. Williams E. Disseminated intravascular coagulation. In: Loscalzo J, Schafer A, eds. Thrombosis and hemorrhage. Boston: Blackwell Science, 1994:921-44.

56. Nawroth PP, Stern DM. Modulation of endothelial cell hemostatic properties by tumour necrosis factor. J Exp Med 1986;163:740-5.

57. Dinarello CA, Cannon JG, Wolff SM. New concepts on the pathogenesis of fever. Rev Infect Dis 1988;10:168-89.

58. Giannoudis PV, Smith RM, Banks RE, et al. Stimulation of inflammatory markers after blunt trauma. Br J Surg 1998;85:986-90.

59. Donnelly SC, Strieter RM, Kunkel SL, et al. Interleukin- 8 and development of adult respiratory distress syndrome in at-risk patient groups. Lancet 1993;341:643-7. 